\title{
From modified radical mastectomy to infra-radical mastectomy: a phase I study for surgical de-escalation focusing on pathological analyses
}

\author{
Veronique Jossa $^{1 \#}$, Fabrice Olivier ${ }^{2 \#}$, Eric Lifrange $^{3}$, André Crevecoeur ${ }^{4}$, Audrey Courtois ${ }^{5}$, \\ Michel Coibion ${ }^{6 *}$, Guy Jerusalem ${ }^{7 *}$
}

${ }^{1}$ Anatomo-Pathology Department, CHC Montlegia, Liege, Belgium; ${ }^{2}$ Medical Oncology Department, University Hospital of Liege, Liege, Belgium; ${ }^{3}$ Senology Department, University Hospital of Liege, Liege, Belgium; ${ }^{4}$ Center of Senology, Liege, Belgium; ${ }^{5}$ Medical Oncology Department, University Hospital of Liege, Liege, Belgium; ${ }^{6}$ Gynecology Department, CHC Montlegia, Liege, Belgium; ${ }^{7}$ Medical Oncology Department, CHU Liège and Liège University, Liege, Belgium

Contributions: (I) Conception and design: V Jossa, M Coibion, G Jerusalem; (II) Administrative support: F Olivier; (III) Provision of study materials or patients: M Coibion, G Jerusalem, E Lifrange, A Crevecoeur, V Jossa; (IV) Collection and assembly of data: V Jossa, F Olivier; (V) Data analysis and interpretation: V Jossa, F Olivier, M Coibion, G Jerusalem, A Crevecoeur; (VI) Manuscript writing: All authors; (VII) Final approval of manuscript: All authors.

\#These authors contributed equally to this work as co-first authors.

*These authors contributed equally to this work as co-last authors.

Correspondence to: Courtois Audrey, PhD. Medical Oncology Department, University Hospital of Liege, Avenue de l'Hopital, 1, 4000 Liege, Belgium. Email: a.courtois@chuliege.be.

Background: Despite that breast conservative therapy became the standard of care in breast cancer, modified radical mastectomy, a large mutilating surgery, is still required for an important number of patients. In order to improve the quality of life and the psychological aspects of a surgery involving the femininity of woman, we developed a new less invasive procedure called infra-radical mastectomy. It aims to save the neckline of patients by the maintenance of the peripheral skin-fatty flap that constitutes the base for implantation of the breast. This phase I study analyzed the feasibility of this procedure using outcome of anatomo-pathological analyses as primary endpoint.

Methods: Between March 2015 and July 2017, all women with operable breast cancer without signs of lymph node invasion were invited to participate in the study in the 2 participating institutions. After a water-assisted dissection of the peri-glandular space, an enucleation of the breast was performed by a cold knife which represents the infra-radical mastectomy. A peri-glandular re-excision (PGR) of the skin and the fat tissue surrounding the gland was then achieved to obtain an MRM. This PGR underwent a careful pathological examination (10 samples per patient). Moreover, the tissue volume and the skin surface of the PGR were quantified.

Results: A total of 53 patients (median age: 60 years) were prospectively recruited. The pathological analysis of peri-glandular biopsies revealed none residual invasive carcinoma, $1 \%$ of biopsies contained focal ductal carcinoma in situ (DCIS) and 0.4\% atypical hyperplasia corresponding to 4 and 2 patients respectively. These 4 patients with residual DCIS were preoperatively diagnosed with extensive DCIS. On average after an infra-radical mastectomy, $37 \%$ of the volume and $53 \%$ of the skin surface of a complete modified radical mastectomy were sparred.

Conclusions: The evaluation of biopsies from peri-glandular tissue suggests that infra-radical mastectomy should be further evaluated except for patients diagnosed with extensive DCIS which must be excluded of this infra-radical approach. Additional work is needed to evaluate cosmetic outcome and impact on quality of life, the need of radiotherapy and the oncological long-term outcome.

Keywords: Modified radical mastectomy (MRM); breast cancer; conservative treatment 
Submitted Jan 22, 2021. Accepted for publication Apr 23, 2021.

doi: $10.21037 / g s-21-48$

View this article at: https://dx.doi.org/10.21037/gs-21-48

\section{Introduction}

Despite that tumours are increasingly diagnosed in early stages and the more frequent use of breast conservative therapy, around $40 \%$ of American and Belgian women affected by early-stage breast cancer still have to undergo a mastectomy $(1,2)$. Indications for mastectomy include extensive breast carcinoma, patient's wishes and prevention of breast cancer in women with genetic predisposition.

The technique of mastectomy evolved over time $(3,4)$. In 1891, Halsted developed the first mastectomy consisting in a monoblock ablation of the breast and pectoral muscles with extended excision of the skin and a radical axillary dissection (5). In 1948, Patey suggested preserving the large pectoral muscle while keeping the other procedures associated with Halsted's intervention (6). In 1972, Madden recommended, in addition to preserving the small pectoral muscle, a reduction in the skin paddle excision and to limit the axillary dissection to Berg's 1st and 2nd level (7). This Modified Radical Mastectomy (MRM) has become the gold standard and is still practiced today by surgeons when conservative surgery is impossible. This procedure is mutilating and reconstruction is sometimes difficult and not always aesthetically satisfying.

To improve the quality of breast reconstruction, less invasive procedures were developed, in particular the SkinSparing Mastectomy (SSM), which consists of a mastectomy but allowing the conservation of a very thin layer of skin by means of a circular peri-areolar incision (8). This technique must be accompanied by an immediate reconstruction. This procedure received a great level of satisfaction in patients due to the preservation of the natural skin envelope of the breast (9).

The challenge in breast cancer surgery is always to obtain "the efficient minimal surgery". For us, an important factor concerns the quality of life of patients involving the perception of their own body and the social impact that it will bring. In concertation with aesthetic surgeons, we developed a new radical mastectomy procedure called the infra-Radical Mastectomy (iRM). The objective is the resection of the entire active mammary gland but the maintenance of the peripheral skin-fatty flap that constitutes the base for implantation of the breast facilitating in this way the reconstruction procedure. With this procedure, the advantage for the patient with a breast amputation is to keep her neckline potentially important for her social live and quality of life. The theory states that a virtual cleavage plane exists between mammary gland and the skinfatty flap and adequate dissection would make it possible resecting the former while allowing the latter to remain in place. The first step to develop this procedure was to analyse the safety using anatomo-pathological criteria. Indeed, patients enrolled in this phase I study have had an infra-radical mastectomy followed by the peri-glandular re-excision (PGR) in order to obtain a total modified radical mastectomy as this represents the gold standard. Pathologic analyses of PGR were used to determine if all malignant glandular tissue was removed with the infraradical mastectomy or if limitations of our procedure could be highlighted. Moreover, a secondary outcome of this study was to measure the surface and volume of the sparring tissue after an iRM which could facilitate the reconstruction of the breast.

We present the following article in accordance with the STROBE reporting checklist (available at https://dx.doi. org/10.21037/gs-21-48).

\section{Methods}

\section{Patients}

This phase I study was proposed to women older than 35 years with operable breast cancer who needed to undergo a mastectomy between March 2015 and July 2017 in two centres (CHC of Liège and CHU of Liège). They must have a T0-3, N0 breast cancer and the tumour could not invade the subcutaneous or pre-pectoral fatty lamina. Breasts were classified using the BI-RADS (Breast Imaging-Reporting And Data System) which is based on radiological density and heterogeneity of fibro-glandular tissue. Only patients with type BI-RADS 1 to 3 were eligible for the study. The study was approved by the ethical committee of University hospital of Liege ( $\left.n^{\circ} 2014 / 289\right)$ and was performed in accordance with the principles of the Declaration of Helsinki (as revised in 2013). The participants gave informed consent before starting the study. 
A

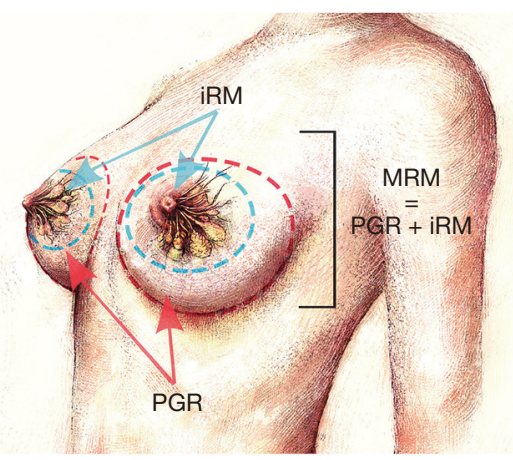

B

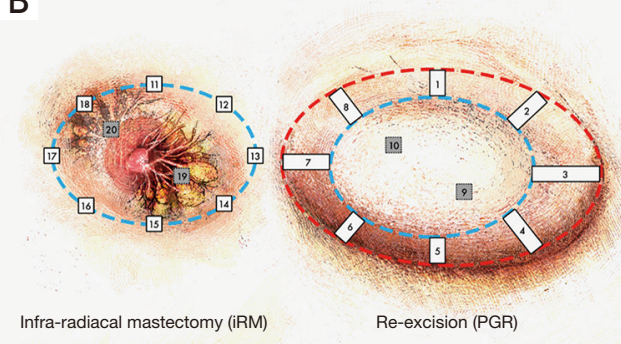

Figure 1 Representative image of surgical procedure (A) and biopsies (B). In blue, the margins of the infra-radical mastectomy (iRM) and in red, margins of modified radical mastectomy (MRM). Sites of biopsies were illustrated by white boxes.

\section{Procedure}

The surgical procedure corresponded to a Madden Type mastectomy (MRM) in two successive stages (Figure 1A). As a first step, an infra-radical mastectomy (iRM) was performed. The cleavage plan between the gland and the peripheral tissue was highlighted and dissected using a liquid infiltration system with a cannula equipped with nutational and infrasonic movement since it was connected to a dedicated piece of equipment (an EVA sp6 device and a LIPOMATIC hand-piece, Euromi, Belgium). The gland, strictly speaking, was then isolated from its surrounding tissue and easily resected.

In the second step, the PGR of the skin and fatty tissue was carried out, the importance of which is dictated by the obligation to obtain a result similar to that of the MRM at the end of this surgery.

\section{Outcomes}

The primary objective of this study was to evaluate the safety of the infra-radical mastectomy procedure based on anatomo-pathological criteria.

The secondary objective was to evaluate the quantity of tissue saved by iRM as compared to MRM.

\section{Assessment methods}

For each patient, ten staggered samples were taken from the PGR: samples 1 to 8 from the circular peripheral re-excision and samples 9 and 10 from the deep pre-pectoral tissue (Figure $1 B$ left panel). With regard to these 10 samples, 10 biopsies were also taken from iRM surgical margins (11 to 20 , Figure $1 B$ right panel). Biopsies were fixed in formol $4 \%$ and $5 \mu \mathrm{m}$ sections were realized. A hematoxylin/eosin staining was used to visualize tissue structure and for each sample, a pathologist classified the tissue into five categories:

(I) Fibrotic and/or fatty tissue without mammary gland (no glands);

(II) Residual benign non-active glands (nonproliferative glands);

(III) Simple glandular hyperplasia and/or adenosis;

(IV) Atypical glandular hyperplasia;

(V) Neoplastic glandular cells [ductal carcinoma in situ (DCIS) or invasive].

To answer to the second objective of the study, the skin surface of total PGR and iRM were measured and used to quantify the percent of skin surface spared while the weight of PGR and iRM were used to quantify the percent of tissue volume spared using two equations:

$$
\begin{aligned}
& \text { Skin surfacespared }(\%)=\frac{\text { Surface PGR }}{\text { Surface } P G r+i R M} \times 100 \\
& \text { Volume of tissuespared }(\%)=\frac{\text { Weight } P G R}{\text { Weight } P G R+i R M} \times 100
\end{aligned}
$$

\section{Statistical analyses}

The nature of the statistical evaluation was explorative. No formal tests were performed. Descriptive statistics (such as median, range, or frequency) are presented for continuous and categorical variables. A bilateral test of proportions with normal approximation was performed on sample categories in order to compare PGR versus iRM using $\mathrm{R}$ software. An alpha of $5 \%$ is used. The $\mathrm{U}$ test was considered as significant if $\mathrm{U} \geq 1.96$.

\section{Results}

\section{Patients and breast cancer characteristics}

In the two centres, 53 patients were enrolled in this 
study. The median age of the 53 patients was 60 years [52-70]. The characteristics of the breast (Bonnet and BIRADS score for the mammography) and of the tumour [histology, tumour-node-metastasis (TNM) stage] are presented in Table 1. The majority of breast cancers presented an invasive form associated with ductal carcinoma in situ (DCIS, 41 patients) while 11 patients presented a pure invasive malignancy and only 1 patient had a pure DCIS. Moreover, pathological analysis of biopsies revealed that 13 patients presented an extensive DCIS while 11 patients showed a vascular or lymphatic vessel invasion. The pathological classes of breast cancers were in majority pT1 $(47 \%)$ or pT2 $(47 \%)$ without positive lymph nodes in half of the cases (55\% N0).

\section{Analysis of PGR and iRM margins}

Among the 53 patients, two cohorts of patients were analyzed, the first 30 patients for whom only PGR were biopsied (cohort A) and the last 23 patients included in the study for whom in addition to PGR biopsies, staggered biopsies within the infra-radical mastectomy margin sections (biopsies 11 to 20) were performed with a total of 228 biopsies at this level (cohort B). The PGR from the 53 patients gave rise to 512 staggered biopsies (Figure 2). Deep samples 9 and 10 were not obtained in the case of nine patients. Characteristics of breast cancers in these two cohorts of patients without or with iRM margin biopsies were similar (Table 1). Table 2 presents the pathologic analyses of the PGR biopsies in the 53 patients. Among

Table 1 Clinicopathological factors of patients for who PGR and surgical margin iRM biopsies were obtained

\begin{tabular}{|c|c|c|c|}
\hline Clinicopathological factors & Total, $\mathrm{N}=53$ & No IRM margin biopsies, $\mathrm{N}=30$ & IRM margin biopsies, $\mathrm{N}=23$ \\
\hline Age, median years (IQR) & $60[52-70]$ & & $60[55-70]$ \\
\hline \multicolumn{4}{|l|}{ Laterality } \\
\hline Left breast & $23(43.4 \%)$ & $14(47 \%)$ & $9(39 \%)$ \\
\hline Right breast & $30(56.6 \%)$ & $16(53 \%)$ & $14(61 \%)$ \\
\hline \multicolumn{4}{|l|}{ Breast size (cup) } \\
\hline B & $18(34 \%)$ & $9(30 \%)$ & $9(39 \%)$ \\
\hline C & $17(32 \%)$ & $10(33 \%)$ & $7(30 \%)$ \\
\hline D & $13(25 \%)$ & $8(27 \%)$ & $5(22 \%)$ \\
\hline$E<$ & $5(9 \%)$ & $3(10 \%)$ & $2(9 \%)$ \\
\hline \multicolumn{4}{|l|}{ Breast density (BIRADS) } \\
\hline 1 & $15(29 \%)$ & $9(30 \%)$ & $6(26 \%)$ \\
\hline 2 & $30(59 \%)$ & $20(67 \%)$ & $10(43 \%)$ \\
\hline 3 & $6(12 \%)$ & $1(3 \%)$ & $5(22 \%)$ \\
\hline NA & 2 & $0(0 \%)$ & $2(9 \%)$ \\
\hline \multicolumn{4}{|l|}{ Breast histology } \\
\hline Pure DCIS & $1(2 \%)$ & $1(3 \%)$ & $0(0 \%)$ \\
\hline Pure invasive (IBC) & $11(21 \%)$ & $7(23 \%)$ & $4(17 \%)$ \\
\hline $\mathrm{DCIS}+\mathrm{IBC}$ & $41(77 \%)$ & $22(73 \%)$ & $19(83 \%)$ \\
\hline \multicolumn{4}{|c|}{ Histologic specific characteristics } \\
\hline Extensive DCIS & $13(25 \%)$ & $9(30 \%)$ & $4(17 \%)$ \\
\hline Vascular or vessels invasion & $11(21 \%)$ & $6(20 \%)$ & $5(22 \%)$ \\
\hline
\end{tabular}

Table 1 (continued) 
Table 1 (continued)

\begin{tabular}{|c|c|c|c|}
\hline Clinicopathological factors & Total, $\mathrm{N}=53$ & No IRM margin biopsies, $\mathrm{N}=30$ & IRM margin biopsies, $\mathrm{N}=23$ \\
\hline 1 & $9(17.3 \%)$ & $3(10 \%)$ & $6(26 \%)$ \\
\hline 2 & $30(57.7 \%)$ & $17(57 \%)$ & $13(57 \%)$ \\
\hline 3 & $13(25 \%)$ & $9(30 \%)$ & $4(17 \%)$ \\
\hline \multicolumn{4}{|l|}{ Tumour } \\
\hline pTis & $1(2 \%)$ & $1(3 \%)$ & $0(0 \%)$ \\
\hline $\mathrm{pT} 1$ & $25(47 \%)$ & $14(47 \%)$ & $11(48 \%)$ \\
\hline pT2 & $25(47 \%)$ & $13(43 \%)$ & $12(52 \%)$ \\
\hline \multicolumn{4}{|l|}{ Nodes } \\
\hline pNO & $29(55 \%)$ & $17(57 \%)$ & $12(52 \%)$ \\
\hline $\mathrm{pN} 1$ & $20(38 \%)$ & $1137 \%)$ & $9(39 \%)$ \\
\hline $\mathrm{pN} 2$ & $2(4 \%)$ & $1(3 \%)$ & $1(4 \%)$ \\
\hline $\mathrm{pN} 3$ & $2(4 \%)$ & $1(3 \%)$ & $1(4 \%)$ \\
\hline \multicolumn{4}{|l|}{ Number of tumour(s) } \\
\hline 1 & $31(58.5 \%)$ & $21(70 \%)$ & $10(43 \%)$ \\
\hline 2 & $14(26.5 \%)$ & $7(23 \%)$ & $7(30 \%)$ \\
\hline
\end{tabular}

iRM, infra-radical mastectomy; IQR, inter-quartile range; IBC, invasive breast carcinoma; PGR, peri-glandular re-excision; DCIS, ductal carcinoma in situ.

the 512 biopsies, $58 \%$ did not contained glands, $39.6 \%$ were composed of non-proliferative benign glands and $1.4 \%$ contained benign proliferative glands. There was no evidence of invasive cancer but ductal carcinoma in situ (DCIS) was found in $1 \%$ of these biopsies. Among the 53 patients, six presented not any glands in PGR biopsies and 35 showed only non-proliferative benign mammary glands. Proliferative glands were found in 12 patients, 6 with benign proliferative glands, 2 with atypical glands and four women have a positive PGR for in-situ carcinoma. These 4 patients were diagnosed with extensive ductal in situ carcinoma associated or not with invasive cancer based on senologic report (a representative patient is illustrated in Figure 2).

As expected, the iRM margins sections were composed in majority with glandular tissue $(80 \%)$. This proportion was significantly higher than in PGR biopsies from the same patients ( $47 \%, \mathrm{U}=7.3$, Table 3). Non-proliferative biopsies represented $70 \%$ of all samples in iRM margins which was also significantly higher than in PGR biopsies (45\%, U $=5.39$ ). Benign proliferative glands and malignant proliferative glands were both found in $5 \%$ of the iRM margins sections (Table 3) which was around four times higher than in PGR biopsies (1.4\% for benign and $1 \%$ for malignant proliferative glands, Table 3). However, as these proportions were less than $5 \%$, the statistical test could not be performed.

\section{Tissue sparing with $i R M$}

The total weigh and surface of PGR and iRM tissue 

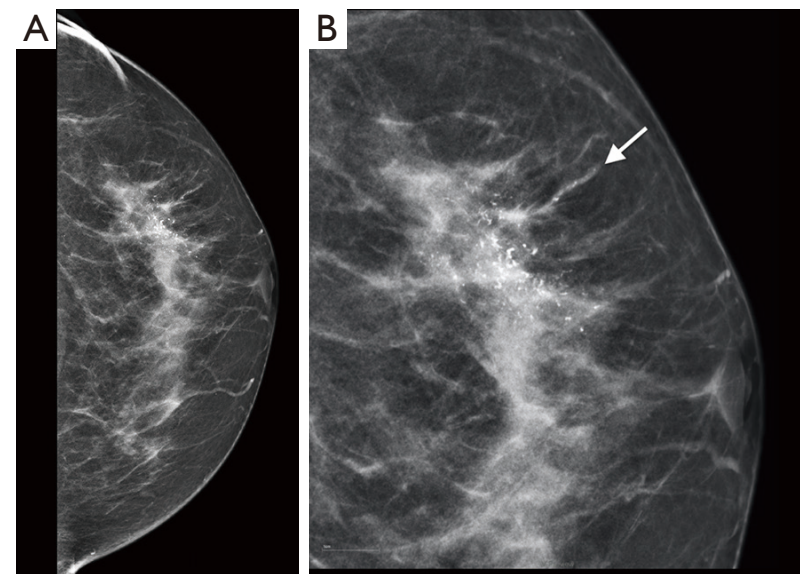

Figure 2 Mammography image of a representative patient with residual malignant carcinoma in peri-glandular re-excision. Diffuse in-situ ductal carcinoma was observed in this patient (arrow in panel B).
Table 2 Pathological analyses of PGR biopsies

\begin{tabular}{lcc}
\hline \multirow{2}{*}{ Pathological characteristics } & \multicolumn{2}{c}{ PGR biopsies } \\
\cline { 2 - 3 } & Patients & Biopsies \\
\hline Total patients/biopsies & 53 & 512 \\
No glands & $6(11.3 \%)$ & $297(58 \%)$ \\
Non-proliferative benign glands & $35(66 \%)$ & $203(39.6 \%)$ \\
Proliferative tissue & & \\
Benign proliferative glands & & $6(1 \%)$ \\
Simple hyperplasia & $6(11.3 \%)$ & $2(0.4 \%)$ \\
Atypical hyperplasia & $2(3.8 \%)$ & $4(1 \%)$ \\
Malignant proliferative glands & & 0 \\
DCIS & $4(7.5 \%)$ & 0 \\
Invasive & 0 & \\
\hline
\end{tabular}

PGR, peri-glandular re-excision; DCIS, ductal carcinoma in situ.

Table 3 Comparison of PGR and surgical margins iRM from the same patients

\begin{tabular}{|c|c|c|c|c|c|}
\hline Pathological characteristics & \multicolumn{2}{|c|}{ PGR biopsies } & \multicolumn{2}{|c|}{ Surgical margin iRM biopsies } & U value \\
\hline Total patients/biopsies & 23 & 226 & 23 & 228 & \\
\hline No glands & $1(4.3 \%)$ & $119(53 \%)$ & 0 & $46(20 \%)$ & 7,30 \\
\hline Non-proliferative benign glands & $16(70 \%)$ & $101(45 \%)$ & $9(39.1 \%)$ & $159(70 \%)$ & 5.39 \\
\hline \multicolumn{6}{|l|}{ Benign proliferative glands } \\
\hline Simple hyperplasia & $3(13 \%)$ & $3(1.3 \%)$ & $4(17.4 \%)$ & $9(4 \%)$ & \\
\hline Atypical hyperplasia & $2(8.7 \%)$ & $2(0.9 \%)$ & $2(8.7 \%)$ & $2(1 \%)$ & \\
\hline \multicolumn{6}{|l|}{ Malignant proliferative glands } \\
\hline
\end{tabular}

Footnote: $U=\frac{P A-P B}{\sqrt{\frac{P A}{N A}+\frac{P B}{N B}}} \sim N(0,1)$ with an $\alpha \leq 0.05 \% \mathrm{U}=|1.96|$. PGR, peri-glandular re-excision; iRM, infra-radical mastectomy; DCIS, ductal carcinoma in situ; NA, not applicable.

resected were measured to quantify the tissue sparing with infra-radical mastectomy compared to Madden radical mastectomy. The mean weight of iRM tissue was $448 \mathrm{~g}$ (range: 133-943) compared to $702 \mathrm{~g}$ (range: 174-1,487) for MRM. The mean skin-surface of iRM was measured at $58 \mathrm{~cm}^{2}$ (range: $17-236$ ) while the MRM was measured to $119 \mathrm{~cm}^{2}$ (range: 42-339). Based on these measures, iRM allowed a tissue sparing corresponding to $37 \%$ (range: 17-62) of the volume of total MRM and the skin surface spared was $53 \%$ (range: $11-75$ ) in comparison to MRM (Table 4). This tissue spared is illustrated on Figure 3 showing the hypothetic result of infra-radical mastectomy (Figure $3 A$ ) compared to modified radical mastectomy (Figure 3B). 
Table 4 Macroscopic characteristics of iRM and PGR tissue excised

\begin{tabular}{lcc}
\hline Macroscopic measures & Tissue weight, mean g (min-max) & Skin surface, mean $\mathrm{cm}^{2}$ (min-max) \\
\hline iRM & $448 \mathrm{~g}[133-943]$ & $58 \mathrm{~cm}^{2}[17-236]$ \\
MRM (iRM+PGR) & $702 \mathrm{~g}[174-1,487]$ & $119 \mathrm{~cm}^{2}[42-339]$ \\
PGR & $254 \mathrm{~g}[41-566]$ & $61 \mathrm{~cm}^{2}[14-174]$ \\
Tissue spared & $37 \%[17-62]$ & $53 \%[11-75]$ \\
\hline
\end{tabular}

iRM, infra-radical mastectomy; MRM, modified radical mastectomy; PGR, peri-glandular re-excision.

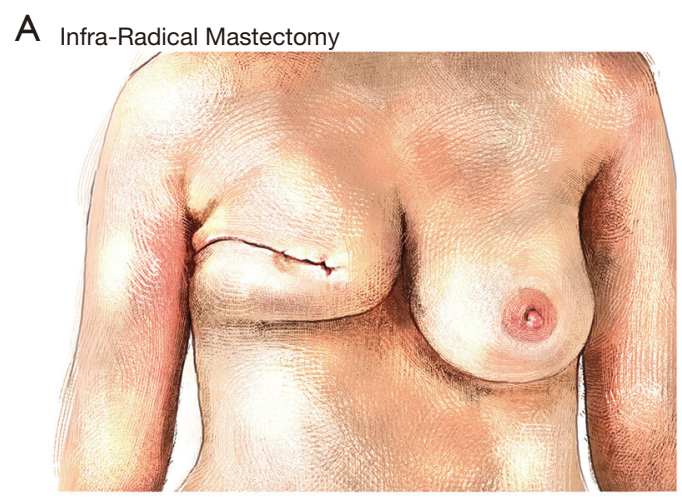

B

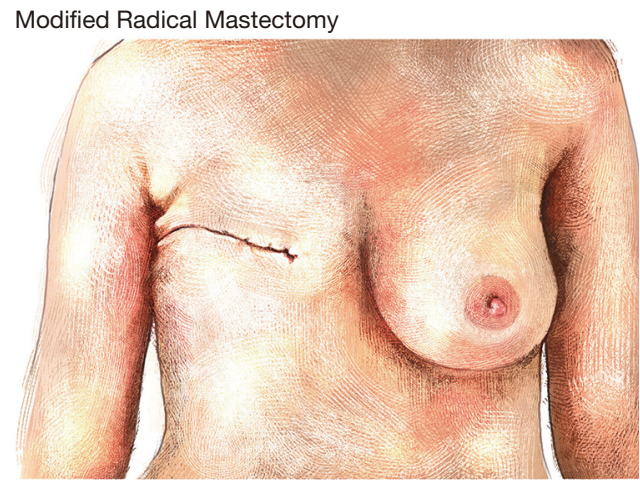

Figure 3 Hypothetic results of infra-radical mastectomy (A) compared to modified radical mastectomy (B). Tissue sparing in infra-radical mastectomy (iRM) should allowed the preservation of the neckline and the basis of the breast.

\section{Discussion}

Since about 50 years, the modified radical mastectomy represents the gold standard worldwide. However, the emergence of new additional therapies including radiotherapy, chemotherapy, endocrine therapy and targeted agents raised the question of the usefulness of standard mastectomy. In 2015, Cossetti et al. compared the hazard rate of relapses (HRR) and overall survival between two cohorts of patients at different time intervals (10). Cohort 1 consisted of patients who underwent surgery between 1986 and 1992 while the second cohort included patients who underwent surgery between 2004 and 2008. The HRR was approximately half in the second cohort compared with the first one up to year seven after surgery. According to the authors, this significant improvement in disease free survival is due to improved management, including the introduction of aromatase inhibitors, taxanes, trastuzumab, regional radiotherapy, tamoxifen for premenopausal women, and prolonged endocrine therapy ranging from 2 to $\geq 5$ years. Based on these results a change in the surgical practice in the direction of de-escalation should be evaluated.

Different studies have shown that mammary glands were still in place after MRM demonstrating that the only radical point about an MRM is in the name. Indeed, small studies indicated that mammary gland tissue was found in the skin and fatty tissue flaps in $20 \%$ of patients undergoing a MRM $(11,12)$. In a similar study realized by Torresan et al. in 2005 focusing on skin-sparring mastectomy (SSM), this proportion increases even to $59.5 \%$ of patients (13). More recently, Griepsma et al. analysed more than 7,000 biopsies sampled on the sections of $206 \mathrm{MRM}$ and found mammary gland tissue in $76.2 \%$ of patients demonstrating that after a radical mastectomy, there is a high probability of residual breast tissue (14). All of these observations could be explained by the anatomical localisation of mammary glands. Indeed, some old studies revealed already that $5-10 \%$ of breast tissue is invisible and localised outside the breast (15-18).

Aware of this imperfection with the standard procedure, we developed a less aggressive surgery in order to facilitate breast reconstruction called infra-radical mastectomy (iRM). In comparison with the SSM or the nipple-sparing mastectomy (NSM), the iRM allowed the preservation of the skin-fatty flap at the level of the implantation of the breast. However, as in complete mastectomy, the nipple and skin surrounding the tumor were removed. In a first step, we presented here a phase I study to evaluate the 
oncological safety of our procedure based on an anatomopathological analysis. As ethical considerations at this stage did not allow the realization of iRM alone in patients, the peri-glandular tissue left in place after this procedure was also removed in order to obtain a complete modified radical mastectomy. Consequently, this phase I study was unable to evaluate the long-term oncological safety, the need for radiotherapy in some patients selected based on clinical or pathological criteria and the aesthetic benefit of iRM. Anatomo-pathological analysis of these biopsies was performed to detect any potential malignant tissue which would remain with iRM. The analyses of PGR showed that in $77 \%$ of patients we found benign and non-proliferative mammary glands similar to what has been reported by Griepsma et al. after standard MRM (14). Moreover, not any residual invasive cancer tissue was found in all PGR samples. However, two $(0.4 \%)$ and four $(1 \%)$ of the biopsies concealed respectively an atypical hyperplasia and DCIS, respectively. In Griepsma's study, also $3.2 \%$ of the patients have cancerous cells in the surgical margins (14) while the failure rate increased even to $8.1 \%$ in the Tewari's cohort (12). In addition, Cao et al. analyzed the superficial margins after a SSM and found that $38 \%$ of superficial margins were positive for residual carcinoma (19). They demonstrated that extensive DCIS could represent a factor predicting positive margins. Indeed, $52 \%$ of cases with residual carcinoma after SSM had extensive DCIS in comparison to $16 \%$ without residual carcinoma.

In our study, among the 53 patients, four of them (7.5\%) have re-excision positive for DCIS. These four positive PGRs were associated with extensive DCIS observed preoperatively by mammography in line with findings reported by Cao et al. after a SSM (19). It seems that patients with extensive DCIS are not good candidates for surgical de-escalation studies. Petit et al. (20) drew the same conclusion in their work on sub-cutaneous mastectomies published in 2012 in which the rate of local recurrence increased from $3.3 \%$ to $8 \%$ when the lesion consisted of partial or total extensive DCIS.

Local recurrence after mastectomy was ranging from $2 \%$ to $9.5 \%$ after a median follow-up of 7 years after mastectomy and its incidence is similar whatever the type of radical surgery was used. Indeed, in a 6-year retrospective study, Kroll et al. reported local recurrence in 7\% and 7.5\% after SSMs and MRMs, respectively (21). After five years of follow-up, Simmons et al. revealed figures of 3.9\% and $3.2 \%$, respectively (22). Moreover, more than $80 \%$ of local recurrences after conservative surgery occurred in the initial tumour bed (23). Therefore, a gradient probably exists in which the risk of tissue cancerisation diminishes the further we are from the original tumour site. Our histological comparison between the PGRs and the surgical margins of iRM showed that proliferative tissue, whether benign or malignant, was found 4 times more often in the margins of iRM than in PGR biopsies in line with this hypothesis. Whatever the nature of the glandular tissue analysed, the difference in the content of these two tissues was highly significant. This led us to believe that the tissue present in PGR is significantly less at risk of local recurrence.

Finally, our preliminary results showed that the iRM saved $37 \%$ and $53 \%$ of the volume and skin, respectively, to be resected in relation to classic mastectomy. In the field of breast surgery, the psychological impact of body image represents an important factor influencing the quality of life of woman during the follow-up. A theoretical representation of the result of iRM taking into account this tissue sparing showed the preservation of the neckline for obvious aesthetic purposes whether or not the patient undergoes breast reconstruction. This preservation of the basis of the breast and the neckline could have a great positive impact on quality of life for women requiring a mastectomy.

In conclusion, for the $30 \%$ to $40 \%$ of patients who still need a mastectomy, it is time to think about de-escalation of the surgical procedure in particular as improved systemic therapy allows a reduction of the risk of local recurrence. The pathologic analyses of this phase I study trend to suggest that infra-radical mastectomy could obtain similar results than radical mastectomy and could represent an alternative of radical surgery with a large improve in aesthetic results for woman. Despite these results, the development of this technique remains at a very early step and should be considered experimental. Further data concerning the need of radiotherapy after iRM, the aesthetic benefit, the impact on quality of life and the longer term oncological outcome are needed before a large prospective randomized trial can be discussed.

\section{Acknowledgments}

Funding: This study was supported by a grant from Belgian Walloon Region, $\mathrm{N}^{\circ} \mathrm{C}-1420184$.

\section{Footnote}

Reporting Checklist: The authors have completed the STROBE checklist. Available at https://dx.doi. 
org/10.21037/gs-21-48

Data Sharing Statement: Available at https://dx.doi. org/10.21037/gs-21-48

Conflicts of Interest: All authors have completed the ICMJE uniform disclosure form (available at https://dx.doi. org/10.21037/gs-21-48). The authors have no conflicts of interest to declare.

Ethical Statement: The authors are accountable for all aspects of the work in ensuring that questions related to the accuracy or integrity of any part of the work are appropriately investigated and resolved. The study was approved by the ethical committee of University Hospital of Liege $\left(\mathrm{n}^{\circ} 2014 / 289\right)$ and was performed in accordance with the principles of the declaration of Helsinki (as revised in 2013). The participants gave informed consent before starting the study.

Open Access Statement: This is an Open Access article distributed in accordance with the Creative Commons Attribution-NonCommercial-NoDerivs 4.0 International License (CC BY-NC-ND 4.0), which permits the noncommercial replication and distribution of the article with the strict proviso that no changes or edits are made and the original work is properly cited (including links to both the formal publication through the relevant DOI and the license). See: https://creativecommons.org/licenses/by-nc-nd/4.0/.

\section{References}

1. Stordeur S, Vrijens F, Beirens K, et al. Indicateurs de qualité en oncologie: Cancer du sein [Internet]. [cited 2020 Nov 26]. Available online: http://www.kce.fgov.be

2. American Cancer Society. Breast Cancer, Facts and Figures 2019-2020. 2020.

3. Plesca M, Bordea C, El Houcheimi B, Ichim E, Blidaru A. Evolution of radical mastectomy for breast cancer. J Med Life 2016;9:183-6.

4. Freeman MD, Gopman JM, Salzberg CA. The evolution of mastectomy surgical technique: from mutilation to medicine. Gland Surg 2018;7:308-15.

5. Halsted WS. I. The Results of Radical Operations for the Cure of Carcinoma of the Breast. Ann Surg 1907;46:1-19.

6. Patey DH, Dyson WH. The prognosis of carcinoma of the breast in relation to the type of operation performed. $\mathrm{Br} \mathrm{J}$ Cancer 1948;2:7-13.
7. Madden JL, Kandalaft S, Bourque RA. Modified radical mastectomy. Ann Surg 1972;175:624-34.

8. Toth BA, Lappert P. Modified skin incisions for mastectomy: the need for plastic surgical input in preoperative planning. Plast Reconstr Surg 1991;87:1048-53.

9. Salhab M, Al Sarakbi W, Joseph A, et al. Skin-sparing mastectomy and immediate breast reconstruction: patient satisfaction and clinical outcome. Int J Clin Oncol 2006;11:51-4.

10. Cossetti RJ, Tyldesley SK, Speers CH, et al. Comparison of breast cancer recurrence and outcome patterns between patients treated from 1986 to 1992 and from 2004 to 2008. J Clin Oncol 2015;33:65-73.

11. Barton FE Jr, English JM, Kingsley WB, et al. Glandular excision in total glandular mastectomy and modified radical mastectomy: a comparison. Plast Reconstr Surg 1991;88:389-92; discussion 393-4.

12. Tewari M, Kumar K, Kumar M, et al. Residual breast tissue in the skin flaps after Patey mastectomy. Indian J Med Res 2004;119:195-7.

13. Torresan RZ, dos Santos CC, Okamura H, et al. Evaluation of residual glandular tissue after skin-sparing mastectomies. Ann Surg Oncol 2005;12:1037-44.

14. Griepsma M, de Roy van Zuidewijn DB, Grond AJ, et al. Residual breast tissue after mastectomy: how often and where is it located? Ann Surg Oncol 2014;21:1260-6.

15. Hicken NF. Mastectomy: a clinical pathologic study demonstrating why most mastectomies result in incomplete removal of the mammary gland. Arch Surg 1940;40:6-14.

16. Goldman LD, Goldwyn RM. Some anatomical considerations of subcutaneous mastectomy. Plast Reconstr Surg 1973;51:501-5.

17. Pennisi VR, Capozzi A. Subcutaneous mastectomy data: a final statistical analysis of 1500 patients. Aesthetic Plast Surg 1989;13:15-21.

18. Baum M, Roberts J. Diseases of the breast. Br J Surg 1986;73:945.

19. Cao D, Tsangaris TN, Kouprina N, et al. The superficial margin of the skin-sparing mastectomy for breast carcinoma: Factors predicting involvement and efficacy of additional margin sampling. Ann Surg Oncol 2008;15:1330-40.

20. Petit JY, Veronesi U, Orecchia R, et al. Risk factors associated with recurrence after nipple-sparing mastectomy for invasive and intraepithelial neoplasia. Ann Oncol 2012;23:2053-8. 
21. Kroll SS, Khoo A. Local recurrence risk after skin-sparing and conventional mastectomy: A 6-year follow-up. Plast Reconstr Surg 1999;104:421-5.

22. Simmons RM, Fish SK, Gayle L, et al. Local and distant recurrence rates in skin-sparing mastectomies compared with non-skin-sparing mastectomies. Ann Surg Oncol

Cite this article as: Jossa V, Olivier F, Lifrange E, Crevecoeur A, Courtois A, Coibion M, Jerusalem G. From modified radical mastectomy to infra-radical mastectomy: a phase I study for surgical de-escalation focusing on pathological analyses. Gland Surg 2021;10(6):1931-1940. doi: 10.21037/gs-21-48
1999;6:676-81.

23. Vaughan A, Dietz JR, Aft R, et al. Patterns of local breast cancer recurrence after skin-sparing mastectomy and immediate breast reconstruction. Am J Surg 2007;194:438-43. 